\title{
THE EFFECT OF INTERNAL AND EXTERNAL FACTORS ON STRATEGIC MANAGEMENT FOR INNOVATION PROCESSES AT THE COMPANY LEVEL
}

\author{
Daniel RUSU*
}

Bucharest University of Economic Studies

\begin{abstract}
It presents the effect that the internal and external factors produce regarding the organization of the operations within the company. The requirement to implement strategic management for the innovation processes present at the company level is motivated. Structural interactions of internal and external factors regarding the organization of the company's operations were identified. Within the strategic management for the innovation processes at the company level, a hierarchy is built for the factors from the internal and external environment.
\end{abstract}

KEYWORDS: companies, external environment, innovation processes, internal environment, strategic management.

DOI: $10.24818 / \mathrm{IMC} / 2021 / 02.19$

\section{INTRODUCTION}

Any company operates and exists in the conditions generated by the internal and external environment. The operation and development of any company is influenced by its internal environment. It could be a source of problems or an expansion for the business and that influences its existence. The indispensable resources of a company in order to support the internal capacities are offered by the external environment. Within any company, internal and external environmental factors generate effects on the decision-making process of management, innovation and general operations. It is also worth mentioning that the weaker performance of companies, among many other reasons, is associated with a specific mechanism of their strategic management but also with the absence of processes characteristic of innovation. Knowledge is the result of specific sets of events, facts, phenomena and actions that can be transformed into models and prototypes capable of being contextually applied within specific organizations (Popa, Ștefan, Morărescu, Cicea, 2018). The fundamental step in the direction of the company's development is represented by the recognition of internal and external factors with repercussions in terms of strategic management of innovation processes. The main objective of this study is to highlight the effect generated by external and internal factors on the strategic management specific to innovation processes at the company level. All these factors primarily influence the competitive position of a company at a given time in a particular market, a position also influenced by the advantages and disadvantages specific to that company compared to other companies in that market but also by performance. its management.

\footnotetext{
*Corresponding author. E-mail address: rusumdaniel@gmail.com
} 


\section{THE STUDY OF THE SPECIALIZED LITERATURE}

The internal and external environmental factors of the company are the subject of specialized studies of many researchers and scientists. A detailed presentation of internal and external environmental factors is provided by Dykan, Zubenko, Makovoz, Tokmakova, Shramenko (2003), which also identified two separate subsystems. In the opinion of ShvetsYu. O. (2016), in order to develop the company, in full accordance with the specifics of its operation, it becomes fundamental to distinguish between internal and external environmental factors. The company's environment is interpreted as factors that have a direct and indirect influence on the company's operations, according to DovhanL, KarakaiYu, Artemenko (2011). The emphasis on the information component, as an important element in the analysis of the internal and external environment, is put by Hevko, Shved (2016). Within situational plans, the internal and external environment is considered as a means of reaction to internal and external threats (Fisunenko, Lazhe, 2016). Hrechan (2005) highlight the importance of shaping the innovation component in he internal and external environment. Strategic management is based on examining both the internal and external environment, with emphasis on external factors as well as management research to improve the company's performance (Fedulova, Kolosh, 2007). For innovative organizations, strategic management is the process by which managers develop strategies necessary to achieve objectives in accordance with the factors involved, external and internal, propose performance objectives and establish long-term orientation (Tolu, Ghiculescu, 2020). Opportunities represent the characteristics of the external environment and have the potential to support the overcoming of the assumed strategic objectives of the organization (Guga, 2010). Companies that develop and implement innovative business models based on innovative and new ways to capture and create value change the way they do business in order to ensure a sustained competitive advantage (Grigorescu, MaerMatei, Mocanu, Zamfir, 2020).

Certain aspects are still to be developed regarding the effects generated by these factors in the strategic management specific to innovation processes at company level, despite a significant stock of literary sources devoted to examining the factors present in the internal and external environment at company level. In the practice of organizations, the specific field of strategic management is defined by theoretical studies that substantiate the necessary conceptual basis in order to describe the innovation process of the business model (Foltean, Glovațchi, (2021). Each organization focuses its efforts on better integration into the business environment. Therefore, the organization has the strategy, know-how and tools necessary to provide efficient and stable feedback for any of the factors present in the evolution of the environment (Gârdan, Andronie, Gârdan, Andronie, Iatagan and Hurloiu, 2018).

The work of Mahmood N. (2012) is based on previous empirical and theoretical studies in order to determine the extent to which contextual factors have a real impact on strategic processes through which decisions are made. Research on contextual factors influencing the process by which strategic decisions are made, according to the results obtained, are restricted or produce contradictory results in studies related especially to the manager's requirement to implement strategic processes necessary for decision making, cognitive conflict, cognitive diversity, industry, heterogeneity, hostility, dynamism, the overall performance of the company, the organizational dimension, the magnitude of the impact as well as the familiarity of the decision. Under the circumstances of the internal and external factors of enterprises, Pearce, Robinson Jr. (1994) establishes the particularities of strategic issues as well as their specificities. The importance of internal and external factors in business processes and product innovation has been studied by Zakic, Jovanovic, Stamatovic, (2008). The factors responsible for the influence of strategic management attitudes are indicated by Marge, Ulle, Toomas (2017). In order to detect the factors that influence the external and internal environment, the factorial analysis is applied. As a result of the research, the following potential critical success factors necessary for the competitiveness of 
organizations present in the creative and cultural industries were analyzed: the orientation towards international cooperation, a highly competitive environment and the absence of financial resources. The theoretical foundation that supports the relationship between organizational performance and strategic management is investigated by Genc, Sengul, (2015). Furthermore, it recognizes the way in which external and internal conjunctural factors have moderating and mediating effects on this relationship and recommends that research examining the correspondence between performance in public sector organizations and strategic management practices could consider the importance of conjunctural parameters.

According to Rajasekar, (2014), the implementation strategy is affected by seven factors. According to the results, by far, leadership is the most important factor that marks the implementation of successful strategy in enterprises. According to Lee, Lee, Pennings, (2001), external networks show the influence on internal and external factors of the enterprise, but the performance of the start-up is predicted only by the interdependence with venture capital firms. A statistically significant influence on performance is held by numerous terms of interaction manifested between the links based on partnership and internal capabilities. The link with financial institutions shows a multiplier effect on the financial resources and technological capacities invested within the enterprises, but those links based on sponsorship do not have individual consequences on the performance. The significance of internal and external factors in creating competitive advantage for SMEs is shown by Kraja, Osmani, (2015).

The present knowledge in this field, according to Rajasekar, (2014), is abundant in industry studies and surveys. Factors responsible for affecting the implementation of the strategy could be ranked by technology, human resources, organizational culture, organizational structure, uncertainty, availability and leadership style. The impact manifested by each of the factors transmits a different force and is present at different levels, even if most of the authors are of the opinion that these factors visibly influence the implementation of the strategy. According to Lorange, (1998), the crucial strategic resources mobilized in the implementation of the strategy are represented by people and not by financial resources because the main center for implementing the strategy becomes symbolized by human resources. Human resource management is achieved through a results-based approach rather than a process-based approach and in turn, this approach is based mainly on employee knowledge and skills (Savin, Cosma, 2020). Cater and Pucko (2008), in a study of a sample of 174 companies in Slovakia, showed that although the biggest obstacle to the execution and implementation of the strategy is poor management, managers rely mainly on organizing and planning activities when strategies are implemented. According to these results, the transposition of the organizational structure in order to support the implementation of the strategy has a positive influence on performance. A particularly important role in the effective implementation of strategic plans is played by human resource management, according to Fulmer (1990). Within the company, human resources management includes all the activities responsible for maintaining, motivating and developing human resources in order to meet the needs of employees and achieve its objectives (Borcoși, 2017). Both the enthusiasm of the employees and that of the organization's departments is particularly important in the process of implementing the strategy. Certainly, a motivating system of rewards but also the involvement of people will generate a positive influence in terms of implementing a certain strategy. For most organizations, human resource management and innovation play a particularly important role in supporting "top" competitiveness in periods of increased competition and rapid change (Dalotă, Perju, 2010).

The importance of examining the external and internal environment in terms of the performance of small and medium companies is determined by Indris, Primiana, (2015).

Most of the development and research activities within a company could be demonstrated with the help of constant factors over time that refer to specific and internal characteristics, such as how to communicate with employees, competitive strategy and managerial dimensions of the company, according to the evidence provided by Griffiths, Webster, (2010). It can be seen that among the 
portion that remained variable over time are relevant the level of research and development activities within the company's industry, the growth rate of that industry and the profits previously obtained. Given the fact that the degree to which the external environment conditions the internal behavior of the company cannot be clearly identified, these results are telling.

\section{THE RESULTS OBTAINED FROM THE RESEARCH}

Under the conditions imposed by the market, the development of a company is closely linked to a rapid response to the changing requirements and needs of consumers and the ability to adapt to them. Strategic management of innovation processes is an important factor for the advancement of the company and consists of a set of tasks and objectives focused on the implementation of new systems, methods and management approaches through the exploitation of internal resources capabilities.

At the company level, the importance of strategic management for innovation processes is justified by their critical role in the economic development of a particular country. Strategic management is the most modern form of company management, forecasting, based on anticipating environmental changes, examination and evaluation of the company's internal potential and changes necessary to harmonize with the external environment to achieve the objectives set and assumed (Borcosi, 2015). The objectives focused on increasing competitiveness must be set by the company's management: developing staff from a professional point of view, introducing innovative approaches in organizing production processes, modernizing or creating technical facilities necessary for the production of services / goods, etc. At the company level, innovation processes are designed to reduce costs or increase the efficiency of fixed assets, which facilitate increased competitiveness and ultimately profit. Each of the measures responsible for improving the company's operation, even measures that are pleasing to innovation, involves considering all internal and external factors with a direct effect on the company's performance.

Because the specific factors of the internal and external environment have effects on many different aspects specific to the operation of the company, even innovation, a certain company must not only be adapted to the external environment but also to optimize its internal structure responsible for opportunities and threats. regarding its development. When examining the opinions of researchers, it is necessary to highlight all these factors by considering the particularity of strategic management specific to innovation processes.

The external environment shows a direct impact on a company (competitors, consumers, contact audiences, partners, resource providers) as well as an indirect impact on it (international events, technological and scientific progress, environmental factors, cultural and social factors, performance economics, government agencies and laws), according to Dovhan, Karakai, Artemenko, (2011).

Also, the external environment is considered as a set of two subsystems that manifest a relative autonomy: micro-environment and macro-environment, according to Dykan, Zubenko, Makovoz, Tokmakova, Shramenko, (2013). The specific factors of the micro-environment are represented by the contact audiences, intermediaries, competitors (general state of competition, activity of competitors and their number), suppliers (suitability of contractual policies, level of attractiveness of suppliers) and consumers (market development but also the evolution and level of consumer demand). Macro-environmental factors include:

- factors specific to the progress of technology and science;

- public welfare; cultural and social factors;

- natural factors: environmental performance in a certain region or country;

- demographic factors: are characterized by the number of the total population; 
- legal factors: the effect of the legislative framework regarding the attitude shown by the government towards small enterprises, the methods necessary for business regulation, commercial activities;

- political factors: the necessary vectors for the development of the political system, the political stability present in a certain region or country;

- economic factors: growth and development of international economic relations, trends and performance of domestic industries, inflation, pensions, the value of wages, change in nonmonetary and monetary income of the population;

Currently, according to the concordant opinions formulated by Hevko, Shveda, (2016), the company's managers receive from the present information systems information focused mainly on the detailed description of the specific parameters of the internal environment (retrospective series on economic performance, production organization, technology ). Unfortunately, information about the external environment is often irregular and fragmented. Moreover, there is no relevant information about consumers, their needs, markets, market competitions, technological and scientific achievements. There is also no political and social information: even within research institutions, the analysis and collection of this information is not adequately carried out. All the above causes the predominance of subjective ideas about the situation of a particular company and outside it and does not allow the adoption of strategic decisions and the construction of sound forecasts.

It is necessary that the factors of the internal and external environment, according to Shvets, (2011), to be divided into specific and general factors, the specific ones incorporating specific characteristics of the process responsible for the management and use of current assets. These factors favor the fulfillment of the control over sales and production in order to monitor the duration of the operating cycle as well as the flows of current assets, the opportunities in terms of participation in profit sharing, the creation of social guarantees for staff and jobs but also a better understanding of objectives. The factors of the external environment, once they have been analyzed, need to be taken into account in order to establish relationships with the government but also with other enterprises, strategy development, selection of economic activities, business planning. The negative effects of these factors must also be mitigated and their positive effects applied, turning the signs of crisis situations and threats into real opportunities for future development.

An examination of the external environment that could be applied, given a plausible increase in processes, in order to assess the long-term capabilities of a company, is conducted by Fisunenko and Lazhe, (2016) and represents the foundation of technological, production, socio-political and macroeconomic forecasts. The predictions of favorable possibilities as well as threats are a determining factor in order to make timely situation plans, which systematizes the development of a strategy necessary for a company to change unfavorable circumstances in better operating conditions and thereby meet its objectives. The current external environment of companies represents a very high level of uncertainty, dynamics but also complexity. Adaptability to changes in external environments is the essential condition in many other fields of activity as well as in business. Moreover, it is the condition for development and survival.

In conclusion, it is essential to specify that companies should be constantly aware of the new nature of environmental changes and thus react operatively to them, on the one hand. We are aware, on the other hand, that in itself, companies produce changes in the external environment by developing new types of services and goods, using new types of technologies, equipment and raw materials. According to Hrechan, (2005), in order to develop the enterprise it is especially important to pay special attention to internal factors (staff attitude towards innovation, management policy in innovation, experience of launching new projects, receptivity to innovation of a company) but and external factors (opportunities for technology marketing, preferential taxation, low refinancing rate, legal framework, acquisition of patents and knowledge, etc.; opportunities to create new mechanisms for promoting products on the market (market innovations); opportunities to develop 
methods new management (management innovations); opportunities necessary to change the social relations within an enterprise (personnel innovations); opportunities for the production of certain new or improved types of services or products).

Using such an approach can bring back to life a new service or a new product, with the help of which a company can make preparations for new technologies needed by staff, can achieve business triangulation, can develop diversification, enter new international markets and all this in order to finally increase its profits.

Within the classification proposed by Fedulova, (2007) internal resources generating innovation capacities, such as legal aspects, patents, external economic relations, technological and scientific skills, employee motivation, organization of professional training, psychological climate, qualification in commercial and marketing activities but also employees' skills are included in category of internal factors. The following are the external factors: risk insurance, operation of infrastructure needed for innovation outside the enterprise, services and patents market, intellectual property protection, external market demand, project author supervision, access to government orders, certification and standardization, loan, financing, supply components and materials, customer and large enterprise relations, taxes, internal market demand. Also, apart from them, it is especially important to form another new group, in which the capacities allow the innovation of a company, namely: patenting abroad, seeking patents, identifying necessary solutions to specific problems of intellectual property protection, expertise in project review. , information support necessary for innovative development, investor search, marketing studies, product certification, adequate information support, compliance of an organization's structure with specific needs in its innovation activities, permanent need to seek to launch new product production, product distribution, participation within the exhibitions, the organization of the production as well as the experimental production installations, the implementation of the technological and scientific developments, the level from the technical point of view of the equipments.

There are still certain factors that need to be considered, according to Zakic, Jovanovic, Stamatovic, (2008). The institutional environment as well as the influence of external stakeholders are particularly important external factors, included in the analysis. The internal factors that are the subject of this analysis contain the costs, the availability of resources, the attitudes as well as the orientation of the relevant decision factors regarding the innovation (managers / owners), personality, etc.

Particularly important gaps are highlighted following a review of the literature by Mahmood, (2012) on external environmental factors. Most previous studies have focused on a specific aspect relevant to external characteristics (stability, for example). Hostility research on strategic decision-making as well as environmental specificity have led to conflicting results while factors such as uncertainty, heterogeneity, speed and hostility have been relatively little taken into account. Those environmental factors responsible for influencing stability, heterogeneity, hostility, the dimensions of dynamism and strategic decision-making proved to be significant.

According to Marge, Ulle, Toomas, (2017), in their daily activities, companies also meet the following challenges: to obtain new orders, to find new customers, to receive external financing, not to trust income, make a profit and be innovative. Moreover, three closely related factors lead companies to act and think strategically: the willingness to expand in foreign markets, the willingness to increase international competitiveness and a challenging environment. Given all these aspects, organizations that act and think strategically are just facing challenges - external or internal.

Usually, strategic problems, according to Pearce II and Robinson (1994), have the following characteristics: they require decisions from top management, require consideration of the external environment of the company, usually have multifunctional consequences, show an orientation towards future, often affects the long-term prosperity of the company and requires a large amount of resources from the company. 
Rational strategic management, according to Genc, Sengul, (2015), is tailored and raised in a structural hierarchy oriented from top to bottom but also on a structure based on rules. Therefore, as an external influencer, central government strategies financially affect organizational performance. Studying school districts in the state of Texas, Meier et. al. (2007) highlighted that in order to maximize performance, organizations need central support. There is an important body of work, contrary to the traditional prominence of the rational approach to strategy, which takes into account the value of the approach from the perspective of the other end of the spectrum, namely the incremental approach. This optimizes the role manifested by the members of the organizations, appreciating them as active participants in the implementation and development stages, an aspect that is supported by the incremental approach. The breakdown of the implementation and formulation stages could lead to the failure of the overall strategy even if, as an internal factor, staff participation supports the improvement of organizational performance. This research provides special practical and theoretical implications for managers and researchers concerned with new business. This research first showed (confirmed) the importance of technological capabilities as well as the financial capital that is invested. In the context defined by new business, in order to establish organizational performance, technological resources are at least as important as the financial resources invested.

Two of the hypotheses that influence the internal and external environment are presented by Indris, Primiana, (2015): Hypothesis 1: performance achieved through the influence of small and medium industries (SMEs) through the analysis of the internal environment; Hypothesis 2: performance achieved through the influence of small and medium-sized industries (SMEs) through the analysis of the external environment.

For corporate policy. mainly the results provided by Griffiths, Webster, (2010) have implications. According to them, in order to be considered innovative, it is necessary in the long run a certain strategy that requires and involves an extensive use of specific communication practices and techniques as well as certain managerial dimensions in order to prevent absorption. It becomes extremely necessary to examine how decision makers can conceive of appropriate managerial behavior. It is very possible to involve attracting another category of people or new ways to hire existing managers, totally different from the current popular suite of meetings and conferences.

\section{Table 1. Internal and external environmental factors}

\begin{tabular}{|c|c|}
\hline The internal environment & The external environment \\
\hline $\begin{array}{l}\text { 1. The impact of tangible assets. } \\
\text { 2. Abilities to forecast and analyze new } \\
\text { possibilities. } \\
\text { 3.Ability to generate business plans and clarify } \\
\text { how ideas can be turned into reality. } \\
\text { 4. Software skills. } \\
\text { 5. Experience, training, skills and abilities at work. } \\
\text { 6. Competence in using technologies. } \\
\text { 7. Capacities and competencies in human } \\
\text { resources management. } \\
\text { 8. Abilities to use and evaluate culture. } \\
\text { 9. Trust and brand name of companies. } \\
\text { 10. Capacities needed to communicate goals and } \\
\text { values. } \\
\text { 11. Relevant competencies for the transmission } \\
\text { and evaluation of knowledge. } \\
\text { 12. Capacities needed to create quality services } \\
\text { and products. }\end{array}$ & $\begin{array}{l}\text { 1. The main force responsible for influencing } \\
\text { competition in a company is the threat of } \\
\text { substitutes. } \\
\text { 2. The main force responsible for influencing } \\
\text { competition in a company is the risk of new } \\
\text { entrants. } \\
\text { 3. The main force responsible for influencing } \\
\text { competition in a company is the bargaining } \\
\text { power of suppliers. } \\
\text { 4. The main force responsible for influencing } \\
\text { competition in a company is the bargaining } \\
\text { power of buyers. } \\
5 \text {. The main force responsible for influencing } \\
\text { competition within a company is the rivalry } \\
\text { between the current competitors }\end{array}$ \\
\hline
\end{tabular}

Source: developed by the author, using Kraja, Osmani, (2015). 
The previously presented review of literary sources approves the determination of structural interactions on the effect of internal and external factors at the company level on the organization of the operation and allows at the same time the construction of a classification for internal and external environmental factors in a specific strategic management context for process innovation. at company level (see Figures 1 and 2).

All the factors that influence the efficiency of the general business management have correlations and show topical issues, necessary to be addressed: increasing the use of innovation, optimizing the quality of services or products, increasing the independence and financial stability of the company, increasing the accommodation of the company regarding the influence of environmental factors, the optimization of the unsatisfactory state manifested by the fixed means of enterprises, the extension of the income level of enterprises, through the reduction of costs, the improvement of production processes as well as the increase of profits.

It is very possible to solve a number of existing problems within an enterprise by optimizing the effectiveness of management. Because of this, due to the influence of these factors, there is an objective need to examine the current situation regarding the efficiency of enterprise management.

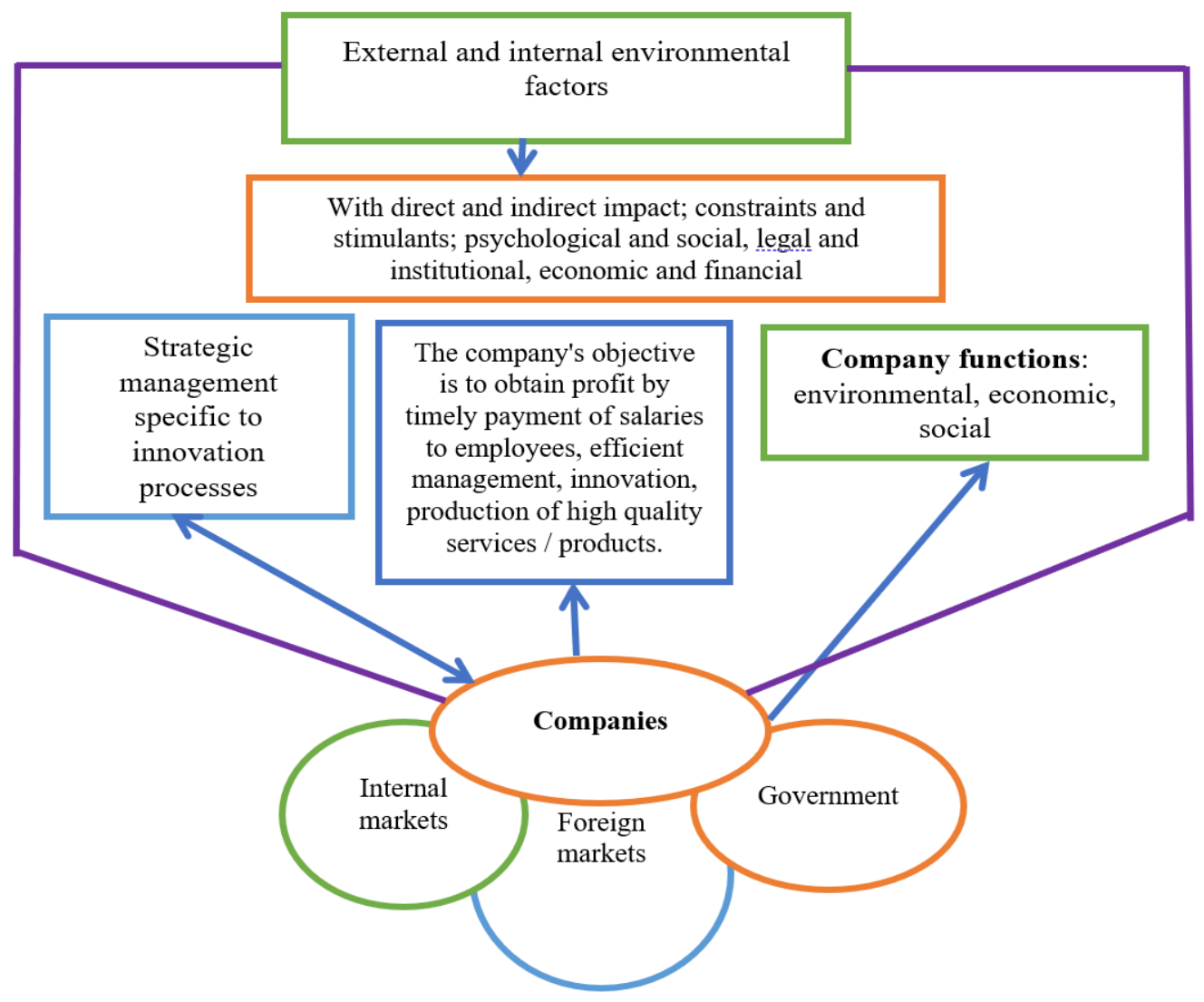

Figure 1. Structural interactions of the impact generated by internal and external factors regarding the organization of operations at the company level.

Source: developed by the author, using (Lorange, (1998); Fedulova, Kolosh, (2007); Zakic, Jovanovic, Stamatovic, (2008); Mahmood, (2012); Fisunenko, Lazhe, (2016), Hevko, Shveda, (2016)).

The practical use of the developed classification (Figure 2) will allow all managers present in the company to identify and measure the factors that have the most significant positive effects for innovation when developing the specific strategy for managing innovation processes as a part integral part of the process of general improvement of the company's management. 
These factors lead to a better understanding of the objectives developed, social guarantees and staff jobs, determining the operational availability of working capital and the period of the operational and financial cycle, more efficient control of the volume of products sold and produced and not in lastly, it creates the possibility of participating in the profit of the distribution. Formed environmental factors, in turn, must be taken into account when establishing relations with the state and enterprises, developing strategy, choosing the field of activity, planning directions and associating negative and positive manifestations of these factors change crisis signals and threats in favorable opportunities particularly necessary for future development.

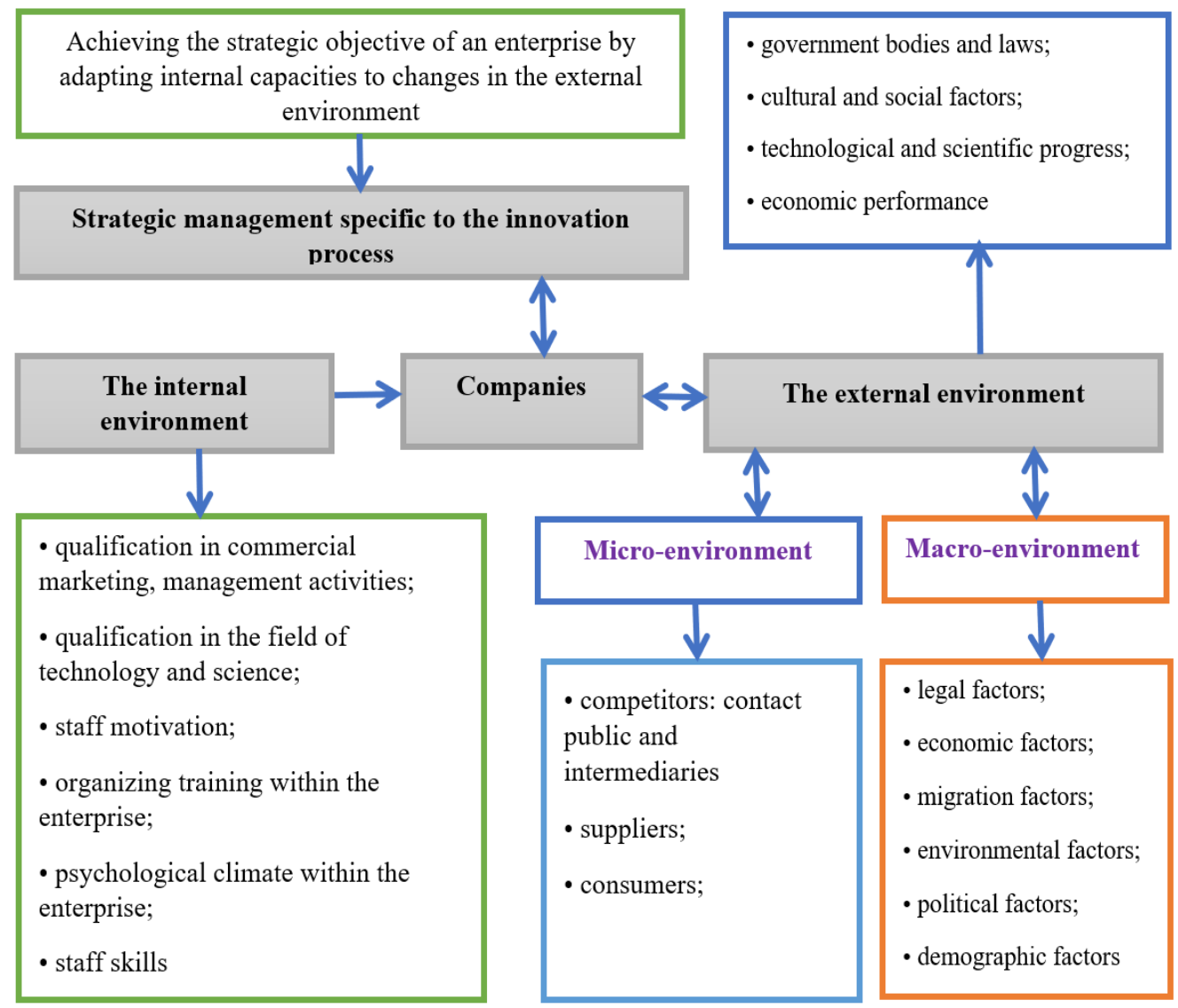

Figure 2. Classification of internal and external environmental factors within the strategic management specific to innovation processes at the company level.

Source: developed by the author, using data from Fulmer, (1990), Lorange, (1998); Rajasekar (2014); Fedulova, Kolosh, (2007); Lee, Lee, Pennings, (2001); Pucko, Cater, (2008); Hrechan (2005); Marge, Ulle, Toomas, (2017); Dovhan, KarakaiYu, Artemenko, (2011)).

In conclusion, contrary to the various approaches in order to analyze and determine the company's environment, standard phases are included in the specific algorithm of the analysis: recognition of internal and external factors with direct effect on the operation of the company; gathering information and data indispensable for research; summarizing and examining its results.

The models of the internal and external environment considered do not consume by far the entire diversity of approaches that exist, but rather reveal the most significant directions in this regard. The practical importance of these models presents differences for different enterprises and economic sectors. At this moment, it is not a single and integrated approach in order to build a general concept for the strategic management of the internal and external environment that comprehensively can combine the parameters of the company's interaction with consumers, 
competitors and partners and political, social, technological influences. and economic. Even in these conditions, a general trend is already manifesting in the strategic analysis.

\section{CONCLUSIONS OF THE STUDY}

It should be noted that researching the internal and external environment of a particular enterprise allows determining its competitive position, the position occupied at a given time in a particular industry and in a certain market segment, determined by managerial performance and its advantages and disadvantages. compared to other companies.

Also, it is not possible to implement the strategic management specific to the innovation processes without taking into account the internal and external factors with effect in terms of the company's operation. The review of the literature authorizes the identification of structural interactions due to the effect of internal and external factors in the organization of operations throughout the company and at the same time allows, in strategic management at the company level, the classification of internal and external factors. It could be useful for the company's managers in proposing technologies but also innovative services / goods, optimizing the work system, examining the efficiency of resources.

\section{REFERENCES}

Borcosi, C. A. (2015), The strategies of enterprises development, Research and Science Today No. 2(10).

Borcoși, C. A. (2017), Human resources, the decisive factor in the development of an organization, Annals of the ,Constantin Brâncuși ” University of Târgu Jiu, Letter and Social Science Series, 1.

Dalotă, M. D., \& Perju, A. (2010), Human Resources Management and the Company's Innovation, Romanian Economic and Business Review, Vol. 5, No. 4.

Dykan V. L., Zubenko V. O., Makovoz O. V., Tokmakova I. V., \& Shramenko O. V. (2013). Strategic management. Kyiv: Center of education literature.

Dovhan L. Ye., Karakai Yu. V., \& Artemenko L. P. (2011). Strategic management. 2nd edition. Kyiv: Center of education literature.

Fedulova L. I., \& Kolosh M. O. (2007). The innovation capacities of an enterprise: a factor for the efficiency of restructuring. Scientific works of Interregional Academy of Personnel Management, 3, 48-56. http://jeou. donnu.edu.ua/article/view/1054/1072.

Fisunenko P. A., \& Lazhe M. V. (2016). Analysis of the factors of external and internal environment for construction enterprises, with impact on the economic security. Business Inform, 10, 189-195. http:// nbuv.gov.ua/UJRN/binf_2016_10_29.

Foltean, F. S., \& Glovațchi, B. (2021), Business Model Innovation for IoT Solutions: An Exploratory Study of Strategic Factors and Expected Outcomes. Amfiteatru Economic, 23(57), 392-411.

Gârdan, D. A., Andronie, M., Gârdan, I. P., Andronie, I. E., Iatagan, M. and Hurloiu, I. (2018), Bioeconomy Development and Using of Intellectual Capital for the Creation of Competitive Advantages by SMEs in the Field of Biotechnology. Amfiteatru Economic, 20(49), 647-666.

Genc E., \& Sengul R. (2015) A Review on the Relationship Between Strategic Management and Performance: The Role of Internal and External Contexts. Strategic Public Management Journal (SPMJ), 2, 56-71. https://dergipark.org.tr/en/download/article-file/274021.

Griffiths W., \& Webster E. (2010) What governs firm-level R\&D: Internal or external factors? Technovation 30, 471-481. http://citeseerx.ist.psu.edu/viewdoc/download?doi=10.1.1.687.8087\&rep=rep1\&type=pdf.

Grigorescu, A., Maer-Matei, M. M., Mocanu, C., \& Zamfir, A. M. (2020). Key Drivers and Skills Needed for Innovative Companies Focused on Sustainability, Sustainability, 12, 102; doi:10.3390/su12010102.

Guga, L. (2010), Environment factors to achieve strategic objectives in companies, Bulletin of the Transilvania University of Braşov • Vol. 3(52).

Hevko O. B., \& Shveda N. M. (2016). Strategic management. Tutorial. For students of all forms of study direction 6.030601 "Management" Ternopil: FOP Palyanitsa V. A., 2016. - 152. 
Hrechan, A. P. (2005). The teoretical foundations for determining the innovation capacities of an enterprise. The economy and the state, 7, 34-37. https://scholar.google.com.ua/scholar?hl=ru\&as _sdt $=0,5 \&$ cluster $=14615790171306777720$.

Indris S., \& Primiana I. (2015). Internal and External Environment Analysis on the Performance of Small and Medium Industries (SMES) In Indonesia. International journal of scientific \& technology research, 4(4), 188-196. https://www.ijstr.org/final-print/apr2015/Internal-And-External-Environment-Analysis-On-ThePerformance-Of-Small-And-Medium-Industries-smes-In Indonesia.pdf.

Kraja Y. B., \& Osmani E. (2015). Importance of external and internal environment in creation of competitive advantage to SMES. (case of SMES, in the or then region of Albania) European Scientific Journal edition, 1.11(13), 120-130. https://eujournal.org/index.php/esj/article/view/5641/5467.

Lorange, P. (1998). Strategy implementation: the new realities. Long Range Planning, 31(1), 18-29, https:// www.sciencedirect.com/science/article/abs/pii/S0024630197000873.

Lee C., Lee, K., \& Pennings, J. M. (2001). Internal Capabilities, External Networks, and Performance: A Study on Technology-Based Ventures. Strategic Management Journal, 22(6-7), 615-640. http://dx.doi. org/10.1002/smj.181.

Mahmood, N. (2012). Factors Influencing Strategic Decision-Making Processes. International Journal of Academic Research in Business and Social Science, 2(7), 405-429. http://hrmars.com/admin/pics/985.pdf.

Marge S., Ulle P., \& Toomas H. (2017). Factors affecting strategic management attitudes and practices in creative industries organisations. Encatc journal of cultural management \&policy, 7(1), 71-87. https://www.encatc. org/media/3723-6_encact-vol-7_marge-sassi_ulle-pihlak-toomas-haldma.pdf.

Rajasekar, J. (2014). Factors affecting Effective Strategy Implementation in a Service Industry: A Study of Electricity Distribution Companies in the Sultanate of Oman. International Journal of Business and Social Science, 5(9(1)), 169-183, http://ijbssnet.com/journals/Vol_5_No_9_1_August_2014/15.pdf

Pearce, J. A. II, \& Robinson, R. B. Jr. (1994). Strategic Management, Formulation, Implementation, and Control, 5th ed. Burr Ridge, Illinois: Irwin inc.

Popa, I., Ștefan, S. C., Morărescu, C., Cicea, C. (2018). Research regarding the Influence of Knowledge Management Practices on Employee Satisfaction in the Romanian Healthcare System. Amfiteatru Economic, 20(49), 553-566.

Pucko, D., \& Cater, T. (2008). A holistic strategy implementation model based on the experiences of Slovenian companies. Economic and Business Review for Central and South - Eastern Europe, 10(4), 307-325. http://www.ijil.ui.ac.id/index.php/tseajm/article/viewFile/1042/958.

Tolu, G., \& Ghiculescu, D. (2020). Strategic analysis of an innovative organization using nonconventional technologies, Nonconventional Technologies Review, Romanian Association of Nonconventional Technologies Romania.

Savin, M., \& Cosma, A. (2020). The importance of diversity management, creativity and innovation in creating a successful company, Challenges of entrpreneurship in the 21st century, No. 32, 2020.

Shvets, Yu. O. (2016). The impact of the factors of external and internal environment on the effectiveness of strategic management of current assets in mechanical engineering enterprises. Bulletin of Zaporizhzhya National University Economics, 1(29), 26-36, http://nbuv.gov.ua/UJRN/Vznu_eco_2016_1_5.

Zakic N., Jovanovic A., \& Stamatovic M. (2008). External and internal factors affecting the product and business process innovation. Facta Universitatis Series: Economics and Organization, 5(1), 17 - 29. http://facta. junis.ni.ac.rs/eao/eao200801/eao200801-03.pdf. 